\title{
Tecnologías del aprendizaje y el conocimiento (TAC) para la traducción de Aristóteles Metafísica 980a-982a'
}

\author{
Ronald Forero-Álvarez \\ ronalfa@unisabana.edu.co \\ Universidad de La Sabana, Bogotá, Colombia
}

\author{
Liliana Andrea Triana-Perdomo \\ latrianap@unal.edu.co \\ Universidad Nacional de Colombia, Bogotá, Colombia
}

\begin{abstract}
Resumen
Este artículo presenta los resultados de la integración de TAC para la lectura, la interpretación y la traducción de Aristóteles en la asignatura de Griego ir impartida en la Universidad de La Sabana. En la primera parte del artículo se explican la motivación, la justificación, los presupuestos teóricos y la metodología seguidos para la inclusión de TAC en el aula de griego, que incluyen la reflexión del docente y la opinión de los estudiantes sobre las clases, así como los resultados de las evaluaciones de semestres anteriores, cuyo fin era determinar un nuevo enfoque didáctico. La segunda parte describe las TAC usadas según las necesidades propias de la enseñanza y el aprendizaje de la traducción de textos: 1) afianzamiento del vocabulario y de las estructuras gramaticales; 2) presentación, interpretación y traducción del texto origen; 3) autoevaluación, coevaluación y evaluación del texto meta. La última parte está dedicada a la presentación de los resultados de la incorporación de las TAC, entre las que destacan la mejora en la motivación de los estudiantes y la posibilidad de su implementación en otros cursos de lengua, pues se favorecen la preparación, el seguimiento, la evaluación y la documentación del proceso de traducción.
\end{abstract}

Palabras clave: TAC, traducción, aula invertida, principio ecléctico, Metafísica

Learning and Knowledge Technologies (LKT) in translating Aristotle Metaphysics 980a-982a

\begin{abstract}
This article presents the results from implementing LKTs in the reading, interpretation, and translation of Aristotle at Greek II course at Universidad de La Sabana. The first part of the article deals with the motivations, justifications, theoretical assumptions, and the methodology followed to include LKTs in this Greek syllabus.
\end{abstract}

$1 \mathrm{El}$ presente artículo es resultado del proyecto de investigación "Unidades didácticas para la enseñanza del griego clásico a estudiantes de Filosofía". El proyecto fue financiado por la Facultad de Filosofía y Ciencias Humanas de la Universidad de La Sabana y se ejecutó entre enero-diciembre del 2018. 
The teacher's reflections and the students' opinions about the lessons were analyzed, as well as the results of previous assessments, in order to design a new didactic approach. The second part describes the LKT used according to the teaching and learning needs related to text translation: 1) strengthening of vocabulary and grammar structures; 2) presentation, interpretation, and translation of the source text; 3) self-assessment, co-assessment and teacher's assessment of the target text. The last part is devoted to the presentation of the results from working with LKTs, underscoring the improvement in student motivation and the possibility of implementing them in other language courses, since they benefit the preparation, monitoring, evaluation and documentation of the translation process.

Keywords: LKT, translation, flipped classroom, eclectic approach, Metaphysics.

\section{Technologies de l'apprentissage et de la connaissance (TICE) pour la traduction de la Métaphysique Aristote 980a-982}

Cet article présente les résultats, dans le cadre d'un cours de grec II mené à l'Université de La Sabana, de l'intégration des TICE dans le processus de lecture, interprétation et traduction d'Aristote. Tout d'abord, nous expliquons la motivation, la justification, le cadre théorique et la méthodologique suivie afin d'inclure les TICE dans le cours. On prend en considération la réflexion de l'enseignant et l'opinion des étudiants sur les cours, ainsi que les résultats des évaluations des semestres précédents, qui visaient à déterminer une nouvelle approche didactique. Ensuite, nous décrivons les TICE utilisés en fonction des besoins de l'enseignement et de l'apprentissage de la traduction des textes: 1) renforcement du vocabulaire et des structures grammaticales ; 2) présentation, interprétation et traduction du texte source ; 3) auto-évaluation, co-évaluation et évaluation du texte cible. Finalement, nous présentons les résultats de l'incorporation des TICE, parmi lesquels on distingue l'amélioration de la motivation des étudiants et la possibilité de la mise en œuvre de ces outils dans d'autres cours de langues car ils favorisent la préparation, le suivi, l'évaluation et la documentation du processus de traduction.

Mots-clés : TICE, traduction, classe inversée, principe éclectique, Métaphysique. 


\section{Introducción}

\subsection{Contextualización}

El presente artículo fue desarrollado en el marco del proyecto de investigación 'Unidades didácticas para la enseñanza del griego clásico a estudiantes de filosofía' de la Facultad de Filosofía y Ciencias Humanas de la Universidad de La Sabana, cuyo objetivo es la implementación de nuevas estrategias metodológicas y de tecnologías del aprendizaje y el conocimiento (TAC) en el curso de Griego II del programa de Filosofía. La necesidad de llevar a cabo dicho proyecto se debió al interés manifestado informalmente por los alumnos de estudiar lenguas clásicas de una manera más amena y motivadora, ya que los manuales para la enseñanza de estas lenguas tienden a seguir una metodología tradicional, fundamentada en la memorización de estructuras gramaticales y de listas de vocabulario y se basan en textos que poco tienen que ver con la filosofía antigua. ${ }^{2}$ La asignatura de Griego il es el último

2 Los métodos seleccionados para la creación de manuales de enseñanza de lenguas clásicas no se adaptan lo suficiente a las necesidades de los estudiantes actuales. Por ejemplo, el método gramática-traducción ha sido tradicionalmente usado en la enseñanza del latín y del griego antiguo, pero ha sido altamente criticado y no se recomienda su uso (Bonilla Carvajal, 2013; Carbonell Martínez, 2010; Martínez, 2008; Richards y Rodgers, 2001; Krashen, 1982). No obstante, hay manuales que se adecúan mejor a los procesos de aprendizaje como Lingua Latina per se Illvstrata, Pars I: Familia Romana

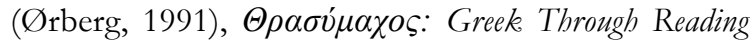
(Munday y Peckett, 2009), Polis: Speaking Ancient Greek as a Living Language (Rico, 2015), los cuales están basados en el método directo y el método situacional, o como $\triangle I A \Lambda O \Gamma O \Sigma$ : prácticas de griego antiguo (Carbone1l, 2014), que tiene un enfoque comunicativo. Asimismo, tenemos conocimiento de dos manuales orientados hacia la lectura de textos filosóficos: Philosophical Greek. An Introduction (Fobes, 1957) y Learning Greek with Plato (Beetham, 2017), ambos de corte tradicional, pues el primero inicia con la traducción de oraciones nivel de los cursos de griego y el segundo de los cursos de lenguas clásicas, pues se dictan también dos cursos de latín. La intensidad horaria es de tres horas presenciales distribuidas en dos bloques, uno de una hora y otro de dos horas. Se espera que el estudiante invierta cuatro horas de trabajo independiente, ya que la asignatura cuenta con dos créditos. La evaluación del curso está dividida en tres cortes, el primero corresponde al $30 \%$, el segundo al $30 \%$ y el tercero al $40 \%$ de la nota final. Los estudiantes inscritos por semestre son pocos, puesto que su número oscila entre siete a doce personas. El curso se apoya en la plataforma Virtual Sabana, una versión de Moodle adaptada para uso de la Universidad de La Sabana (vid. sección 2.1.1).

\subsection{Metodología de investigación y presupuestos teóricos}

\subsubsection{Investigación-acción}

Se siguió la metodología de la investigación-acción en sus tres etapas (interés técnico, trabajo de campo e interés emancipatorio), las cuales permiten comprender y transformar las prácticas pedagógicas mediante la reflexión acerca de la labor profesional y la participación de los estudiantes (Kemmis y MacTaggart, 1988; Lewin, 1946; Martínez Miguélez, 2000; Restrepo Gómez, 2009). En la primera etapa (interés técnico), se analizaron las respuestas de los estudiantes a una encuesta anónima de tres preguntas enviada por medio de Google Drive ${ }^{\circledR}$ (vid. Tablas 1 a 3). La encuesta, de participación voluntaria, se realizó después de la finalización

cortas que se van volviendo más complejas hasta llegar a una selección de textos de Platón, de Menandro y, mayoritariamente, de Aristóteles; el segundo prepara al alumnado para su familiarización con el estilo de escritura de Platón, por medio de frases y fragmentos tomados del Menón, que van incrementando su grado de dificultad. 
de las clases del segundo semestre de 2016 entre 19 informantes, alumnos de los cursos de Griego i y ir y Latín I y il de la Universidad de la Sabana (vid. Figura 1).
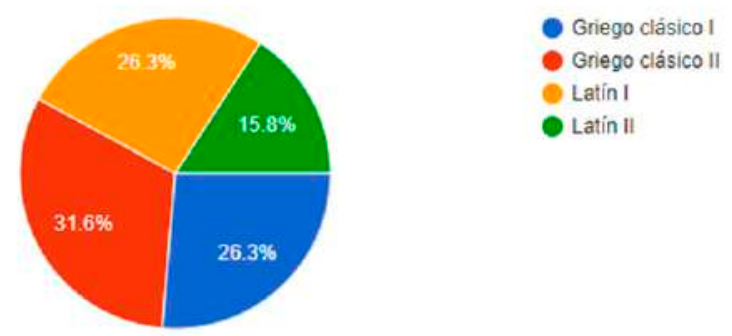

Figura 1. Porcentaje de participación por grupo

Las tablas 1 a 3 resumen en categorías las sugerencias de los estudiantes en relación con las preguntas de la encuesta. ${ }^{3}$

El análisis de los datos obtenidos sugiere que los estudiantes desean un cambio en la didáctica, las actividades de clase y el uso de TAC. Consideramos que las respuestas relacionadas con los aspectos didácticos se deben a que los estudiantes prefieren otro tipo de materiales, diferente a los manuales usados, ${ }^{4}$ tales como

3 La reducción y categorización de los datos se realizó siguiendo el modelo de codificación propuesto por Taylor y Bogdan (1992).

4 Los manuales usados son A $\theta \dot{\eta} v \alpha \zeta \varepsilon:$ An Introduction to Ancient Greek (Balme, Lawwal y Morwood, 1990) y Oxford Latin Course (Balme y Morwood, 2006). Ambos se fundamentan en el método directo. Estos manuales se caracterizan por el uso activo de la lengua enseñada y el apoyo de imágenes, demostraciones, mímicas o explicaciones, evitando en la medida de lo posible el uso de la lengua materna del aprendiz. De esta manera, se espera que el alumnado adquiera vocabulario con facilidad, sea capaz de intuir las reglas gramaticales y desarrolle gradualmente su habilidad comunicativa. Sin embargo, este método tiene desventajas, como la exigencia al profesor de hablar la lengua enseñada y la temprana insistencia en los aspectos gramaticales que pueden causar estrés y ansiedad. Asimismo, requiere una gran cantidad imágenes y videos, pues están inmersos en una cultura visual y se sienten más cercanos a la tecnología audiovisual e informática que las generaciones anteriores (Dussel, 2009).

En consonancia con lo anterior, los estudiantes consideran que la metodología de la clase es monótona, pues la lectura y el análisis por turnos de las lecturas graduadas de los manuales y la preparación de ejercicios escritos no resultan motivadores ni entretenido, al tiempo que insisten en la creación de actividades lúdicas e interactivas. Asimismo, es manifiesto el deseo de traducir textos filosóficos y otro tipo de textos diferentes a los que se encuentran en el manual, pues suponemos que las lecturas les resultan poco significativas, lo cual explicaría la dificultad en la memorización del vocabulario, uno de los aspectos en los que los estudiantes presentan el rendimiento más bajo en las calificaciones.

Por otra parte, el uso de TAC resulta notablemente interesante, puesto que, aunque la mayoría de los aprendices considera que deben incluirse $(57,14 \%)$ en las clases, seis de ellos $(42,85 \%)$ manifestaron que son innecesarias, poco relevantes o tediosas. Este rechazo puede deberse a experiencias desafortunadas en la implementación de TAC en el aula o en las plataformas como Virtual Sabana por parte de los profesores, como puede deducirse de las siguientes respuestas a la tercera pregunta:

"Los dispositivos electrónicos pueden ser útiles, si, por ejemplo, existen juegos en internet de vocabulario o actividades de repaso, de lo contrario la clase no debería ser dictada utilizando diapositivas, ya que genera distracción y no genera utilidad"

"Las actividades en Virtual Sabana son muy buenas, ayudan a practicar pero son tediosas"

"No, no me gustaría. Detesto Virtual Sabana”.

de tiempo para garantizar buenos resultados (Krashen, 1982; Richards y Rodgers, 2001). 
Tabla 1. Primera pregunta de la encuesta

\begin{tabular}{lc}
\hline ¿Cómo te gustaría que se dieran las clases de griego y latín? & $\begin{array}{c}\text { Número de } \\
\text { comentarios }\end{array}$ \\
\hline Uso de otro tipo de recursos en el aula como imágenes y videos & 7 \\
\hline Reducción de la monotonía en las clases & 4 \\
\hline Contenidos históricos y culturales & 2 \\
\hline Énfasis en etimología & 2 \\
\hline Énfasis en el vocabulario filosófico & 1 \\
\hline Énfasis en la utilidad de las lenguas clásicas para aprender lenguas modernas & 1 \\
\hline Explicaciones más adecuadas de la gramática & 1 \\
\hline
\end{tabular}

Tabla 2. Segunda pregunta de la encuesta

¿Qué tipo de actividades te gustaría que se realizaran en clase?

Número de comentarios

Traducción de textos filosóficos o literarios 13

Actividades lúdicas (interpretación de poemas y canciones, juegos de vocabulario y gramática, dramatizaciones)

Visualización y comentario crítico de películas y documentales sobre la Antigüedad

Actividades de trabajo independiente fuera del aula

1

Exposiciones

Práctica de expresión oral y escrita

1

Diálogos

1

Tabla 3. Tercera pregunta de la encuesta

\section{¿Te gustaría que se usaran dispositivos electrónicos?, ¿de qué manera?}

TAC y Virtual Sabana para aprender vocabulario y gramática

Uso de tac y Virtual Sabana es innecesario, irrelevante o tedioso

Más uso de actividades en Virtual Sabana

Dispositivos móviles (portátiles y celulares)

Juegos en internet para el vocabulario (Kahoot!)

Proyector
Número de comentarios
6

4

4

3

1 
Basándonos en la información proporcionada por las respuestas de los alumnos en el cuestionario virtual, la segunda etapa de la investigación (el trabajo de campo) consistió en la planeación de la transformación de la práctica pedagógica, es decir, en el diseño de un plan de acción que mejoraría las clases. Se consideró que dicha transformación tendría que iniciarse en el último corte del curso de Griego II, mediante la creación de una unidad didáctica enfocada en la traducción de textos filosóficos, ya que los estudiantes insistieron en este tipo de actividad. Dicha unidad serviría de piloto y de modelo para desarrollar las demás unidades didácticas realizadas durante las siguientes etapas del proyecto. Se escogió esta parte de los cursos, debido a que los contenidos gramaticales y léxicos del manual de clase preparan a los estudiantes para la lectura de textos de mediana dificultad, de modo que este último corte sería el ideal para intentar la traducción de un texto filosófico de autor sin adaptaciones. Así, la unidad didáctica tendría que cambiar radicalmente el desarrollo de las clases, por medio de la utilización de otro tipo de materiales educativos y la inclusión de TAC, que tendría en cuenta los criterios de relevancia, pertinencia, eficacia y entretenimiento. Por otra parte, dado que se iban a incluir nuevos contenidos relacionados con competencias de traducción, se tendría que modificar el sistema de evaluación formativa que se estaba implementando en los cursos (vid. infra sección 3).

La tercera etapa (interés emancipatorio) expone el análisis y la reflexión en torno a los resultados de la implementación de la unidad didáctica y el proceso llevado a cabo en la investigación (vid. infra sección 4). Dicha etapa será presentada en las conclusiones de este trabajo, de manera que se pueda presentar a continuación la planeación y el diseño de la nueva práctica pedagógica.

\subsubsection{Aristóteles}

La selección del texto filosófico en el que se centraría la unidad didáctica se basó en los siguientes criterios: ${ }^{5}(1)$ continuidad en la materia que trata el texto con el fin de que la clase pueda concentrarse en los aspectos específicos del proceso de traducción; (2) relevancia profesional que estimule el desarrollo de conocimiento relacionado con su actividad en los futuros profesionales; (3) realismo profesional que asegure que el texto corresponde en la medida de lo posible a situaciones profesionales reales; (4) grado de dificultad que se ajuste a las diferentes etapas del proceso de aprendizaje, permitiendo así el desarrollo de la confianza en los estudiantes; (5) función textual reconocible; (6) accesibilidad del contenido que permita a los estudiantes entender el tema del texto; (7) necesidad de investigación documental y terminológica que suscite la búsqueda y consulta de diferentes fuentes para la comprensión del texto.

Tras analizar varios textos y autores, se decidió que la introducción de la Metafísica (980a-982a) se ajustaba a los criterios expuestos. Por una parte, es un texto argumentativo-expositivo, en el que no aparecen formas dialectales o poéticas y el lenguaje usado es particularmente técnico, sin presencia de estructuras gramaticales demasiado complejas. Por otra parte, Aristóteles, junto con Sócrates y Platón, son los filósofos más conocidos de la Antigüedad. De hecho, Aristóteles es

5 Adaptados a partir de los criterios expuestos por Kelly (2000), pues se trata de la elección de un texto filosófico antiguo, de manera que criterios como experiencia textual, elementos no verbales, calidad de los originales y competencia interpersonal (traductor y cliente) no son pertinentes. 
aún citado como punto de partida para muchos estudios humanísticos, pues se esforzó en sistematizar sus indagaciones filosóficas e incursionó en una gran variedad de materias, que lo convirtieron en un modelo para muchos pensadores a lo largo de la historia (Donini, 2014; Horneffer, 2008). El estagirita también fue el primer filósofo en plantearse los problemas sobre la búsqueda de una ciencia más fundamental y más universal, a la que denominó 'filosofía primera' (Cohen, 2016; Grondin, 2014). Además, en la Metafisica Aristóteles estudia por primera vez los problemas de objetos suprasensibles que siguen siendo los problemas de la metafísica occidental (Reeve, 2000). A estos temas se enfrentan los estudiantes de filosofía en los cursos de los primeros semestres del pregrado, tales como Historia de la Filosofía Antigua, Introducción a la Filosofía o Seminario de Filosofía Antigua; de manera que estudiar este texto resulta para ellos particularmente significativo.

\subsubsection{Principio ecléctico y aula invertida}

Para llevar a cabo una efectiva transformación pedagógica de la asignatura, se consideró que sería pertinente seguir el principio ecléctico para el diseño de las actividades, el cual nos permite combinar distintos métodos y enfoques de la enseñanza de idiomas, de acuerdo con los objetivos de la clase. La planeación de un curso desde esta perspectiva debe abarcar la selección y la unión adecuada de distintas estrategias metodológicas y teóricas, con el fin de lograr mejores resultados. Adicionalmente, se deben tener en cuenta aspectos como la claridad en los objetivos del curso, el protagonismo del estudiante en el aula, el rol del docente 'ecléctico', la claridad en las distintas estrategias que se utilizan y la contextualización y la pertinencia de los contenidos. Por otra parte, en este principio, la formación teórica, la experiencia y la personalidad del docente son fundamentales. El profesor debe tener el conocimiento, la formación y la capacidad de elegir entre la variedad de las posibilidades metodológicas que se le presentan. Además, en la planeación de un curso debe aplicar los criterios de selección, secuencia, pertinencia y coherencia según las necesidades de los estudiantes, para lo cual le es de gran utilidad la experiencia docente y personal (Praveen, 2013; Salazar y Batista, 2005).

Por otro lado, debido a la poca duración de las clases presenciales en la semana, se pensó en que el modelo de Aula invertida sería el más adecuado para fomentar el aprendizaje de los contenidos lingüísticos de la asignatura. Dicho modelo consiste en proporcionar material didáctico a los alumnos sobre determinados aspectos, para que los estudien desde su casa y lleguen a la clase preparados para practicarlos. De esta manera, al trasladarse el aula fuera, cada estudiante puede aprender y estudiar según su propio ritmo sin interferir en el de los demás. Ello, a su vez, aporta la ventaja de que se aproveche mejor el tiempo de clase, ya que se realizan actividades que faciliten, potencialicen e involucren el desarrollo de procesos cognitivos de mayor complejidad con la ayuda del docente (Lowell y Verleger, 2013; Santiago, 2018). En el aula invertida, es necesario que el profesor conozca, elija y reflexione sobre los diversos recursos digitales disponibles para la preparación del estudio independiente, es decir, el que se hace de forma autónoma desde la casa, y las lecciones presenciales.

Este modelo permite varias innovaciones pedagógicas, generadas por la combinación de distintas metodologías y el uso de la tecnología. Se pueden utilizar videos y audios que ya estén dispuestos en la red, pero también pueden ser creados por los docentes o los estudiantes. Una ventaja de los recursos digitales 
es que pueden modificarse según su finalidad, sin la necesidad de tener vastos conocimientos de programación.

Otra característica destacable de este modelo es que el alumnado tiene la oportunidad de acceder repetidamente a los contenidos y a las actividades propuestas. De esta manera, el aprendizaje se convierte en un proceso constructivo entre estudiantes y profesores, en el que el alumno no solo coopera y colabora, sino que también discute, argumenta, crea, desarrolla habilidades metacognitivas y evalúa su propio aprendizaje (Tucker, 2012). Durante la clase, el profesor guía el proceso de aprendizaje y facilita la participación activa de los estudiantes. Asimismo, se simplifica el seguimiento de los avances en el proceso de aprendizaje gracias al uso de TAC (Richards, 2017). Así, el docente puede evaluar y retroalimentar el desempeño de los alumnos de forma inmediata y de manera personalizada o grupal. Además, se puede fomentar en el estudiante la exploración, la articulación y la aplicación de ideas a través de preguntas, discusiones y actividades.

Según lo expuesto, se puede concluir que en el aula invertida los alumnos se comprometen con su proceso de adquisición de la lengua, reciben atención personalizada del docente, disponen de varios recursos y actividades, de manera que el salón de clase se transforma en un espacio donde se comparten ideas y se fortalece el pensamiento crítico, analítico y creativo (Roehl, Reddy y Shannon, 2013).

\subsubsection{Competencias de traducción}

Dado que la unidad se centraría en la traducción de un texto de autor sin adaptar, se determinó que el desarrollo de competencias específicas de traducción sería fundamental, ya que los textos antiguos presentan dificul- tades especiales por la distancia lingüística, temporal y cultural entre el traductor y el texto origen, que involucran la pérdida en muchos casos (de parte) del contexto sociocultural en el cual los textos fueron producidos. ${ }^{6}$ Asimismo, la recuperación total de los matices semánticos de textos especializados como el de Aristóteles es problemática, en la medida en que el vocabulario filosófico estaba en proceso de especialización a partir del uso y la transformación del registro estándar. Por otra parte, dichas dificultades se incrementan si se trata de un estudiante de filosofía y no de una persona que se está formando como traductor. De manera que encontrar competencias básicas de traducción que pudieran enseñarse en un aula con las características de un curso de lengua para estudiantes de filosofía requirió criterios de pertinencia y eficacia.

Para la formulación de las competencias traductológicas, se partió de la identificación de los errores más comunes cometidos por los alumnos en sus exámenes escritos para establecer los problemas que debían solucionar mediante el desarrollo de competencias. E1 análisis de las pruebas escritas dio como resultado dos grupos de errores. ${ }^{7}$ El primer grupo fue conformado por los errores de comprensión lingüística del texto origen, un aspecto fundamental para el aprendizaje de una lengua sintética de casos como el griego antiguo, en el que el correcto análisis morfosintáctico resulta indispensable para identificar las funciones de las palabras en una oración. En el segundo grupo se incluyeron los errores de expresión de las ideas del texto origen en el texto meta, los cuales, a su vez, se dividieron en cuatro subgrupos: 1) léxico: dificultad de

6 Sobre las dificultades de la traducción de textos antiguos, remitimos a Roberts (1997) y Hardwick (2000).

7 Partimos de la tipología expuesta por Kim (2009) y Beeby (2000). 
encontrar equivalencia de palabras y expresiones griegas en español; 2) transferencia de las ideas: omisiones y adiciones de información que afectaban la transmisión de la ideas, las divergencias de sentido del texto meta en relación con el texto origen, los calcos de estructuras gramaticales y léxicas griegas que perjudican la comprensión de las idea en el texto meta, el hipérbaton en el texto meta que obstaculiza su fácil comprensión; 3) redacción: coherencia, cohesión, adecuación y claridad; y 4) forma: ortografía, acentuación, puntuación y caligrafía.

A partir de lo anterior, las competencias para desarrollar en los estudiantes serían a) la capacidad de comprender el texto griego a nivel morfosintáctico; b) la habilidad de encontrar equivalencias de conceptos y expresiones griegas en la lengua meta; y c) la destreza en la transferencia de las ideas de una lengua a otra. Para su desarrollo en el aula se tuvo en cuenta la metodología basada en el error propuesta por Hurtado (1994, 1995), en la que el diagnóstico, la autoevaluación del estudiante, el aprendizaje de los errores, la resolución de los problemas de diversas maneras dependiendo del tipo de error y la aplicación de criterios de manera progresiva son fácilmente aplicables en las clases de lenguas clásicas, puesto que los estudiantes presentan clase a clase versiones de textos griegos. Asimismo, el diseño y la presentación en clase de las rúbricas de evaluación contribuyeron a una formación más consciente y práctica del proceso de traducción (vid. sección 3).

\section{Unidad didáctica}

A continuación, presentamos la unidad didáctica diseñada a partir de los presupuestos teóricos expuestos. La unidad fue insertada en Virtual Sabana para que los estudiantes tuvieran acceso a ella desde cualquier dispositivo y fue dividida en las siguientes partes: a. Prolegómena ${ }^{8}$ (prolegómenos, preámbulos) comprende: a) los contenidos filosóficos, culturales y gramaticales de la unidad; b) los tipos de texto y léxico y los componentes estratégicos desarrollados; y c) una breve introducción a la Metafisica de Aristóteles.

b. Boethémata (recursos, ayudas) es una sección en la que se encuentran enlaces a herramientas disponibles en la red para el estudio del griego clásico. También cuenta con una nube de palabras y gráficos de frecuencia de los lemas y las formas más comunes en la Metafisica, una wiki colaborativa y videos con la gramática esencial que se necesita para comprender el texto aristotélico.

c. Progymnásmata (ejercicios preparatorios) reúne los ejercicios previos al análisis del texto origen que consisten en actividades en SuperMemo, PurposeGames, EducaPlay y Moodle.

d. To tu Aristotélus érgon (la obra de Aristóteles) presenta el texto origen en OneNote.

e. Gymnásmata (ejercicios) incluye actividades de repaso en Moodle, Quizzizz y Kahoot!

\section{f. Autoevaluaciones y coevaluaciones}

\section{g. Calificaciones}

La implementación de la unidad se hizo de la siguiente manera: 1) se presentó en la primera clase del tercer corte la unidad, proyectando en el aula las distintas secciones de las que está compuesta; 2) se explicó el cambio didáctico en relación con los cortes anteriores, haciendo

8 Ofrecemos una transcripción de los términos griegos, pero en la unidad se encuentran en griego clásico. Se intentó en toda la unidad utilizar la mayor cantidad de palabras e instrucciones en la lengua origen para aumentar el imput en los estudiantes. 
especial énfasis en el trabajo preparatorio e independiente necesario para aplicar el modelo de aula invertida en las siguientes sesiones.

Gracias a la aplicación de los principios de esta nueva dinámica, se dio un giro radical a la manera en la que se dictaba la clase. La primera sesión de la unidad didáctica inició con actividades de calentamiento cuyo objetivo era aprender y afianzar tanto el vocabulario como las estructuras gramaticales del texto origen. Es decir, no se siguió la forma tradicional en la que los estudiantes empiezan a trabajar con el texto traduciéndolo, mediante el uso de diccionarios y gramáticas, sino con ejercicios motivadores. Dichos ejercicios estaban apoyados por TAC, incluían el componente lúdico y eran cooperativos. ${ }^{9}$ Asimismo, desde los dos cortes anteriores se familiarizó a los estudiantes con las competencias de traducción por medio de la presentación de la rúbrica y los criterios que se evaluarían (vid. infra sección 3). Una vez terminadas las actividades preparatorias, se procedió al análisis del texto origen, siguiendo la misma metodología de Aula invertida, esto es, dejándoles como tarea fuera del aula la preparación de una versión del texto. Después de terminar el texto, se procedió a los ejercicios de repaso y a la prueba escrita.

9 La primera actividad, denominada ainígmata tu sómatos (Enigmas del cuerpo), buscaba afianzar las oraciones de acusativo con infinitivo, el infinitivo sustantivado y las oraciones finales con hina. Para su realización se crearon juegos en las plataformas PurposeGames y EducaPlay. La segunda, nombrada tís estin; (¿Quién es?), reforzaba los adjetivos, los grados del adjetivo y las oraciones comparativas y superlativas. La tercera, llamada kryptoi pápyroi (Papiros ocultos), repasaba la tercera declinación y los verbos en voz media y se llevó a cabo mediante la creación de cuestionarios en Kahoot! La última, titulada mythidia (Historietas), comprendía los participios sustantivados, para la cual los estudiantes usaron editores de gráficos según la disponibilidad de sus computadores.

\subsection{Descripción de las TAC}

A continuación, presentamos las TAC seleccionadas y utilizadas en la unidad. El objetivo de este apartado es ofrecer una propuesta de implementación y una descripción de su forma de uso.

\subsubsection{Afianzamiento del vocabulario $y$ de las estructuras gramaticales}

La Universidad de La Sabana cuenta con la plataforma Virtual Sabana, basada en Moodle y de uso institucional, la cual se seleccionó para la implementación de la unidad didáctica y algunas de sus actividades. Moodle es un software libre que, por un lado, posibilita la creación de unidades didácticas y el fomento del autoaprendizaje, el aprendizaje cooperativo y la creatividad y, por otro, se completa con la web 2.0 (Ros Martínez de Lahidalga, 2008). Además, permite la gestión de los cursos, la comunicación con los estudiantes y la realización y el seguimiento de la evaluación del curso (Lerís, Vea y Velamazán, 2015; Sánchez Santamaría, Sánchez Antolín y Ramos Pardo, 2012). De este modo, para la lectura, la interpretación y la traducción del texto de Aristóteles se buscaron primero herramientas que ayudaran a los estudiantes a afianzar la adquisición de vocabulario y de estructuras gramaticales en Virtual Sabana, que se complementarían con las aplicaciones SuperMemo, Kahoot!, Quizizz, entre otras.

Para el afianzamiento del vocabulario se sugirieron las siguientes actividades. En primer lugar, se diseñaron unas en forma de cuestionario en Virtual Sabana para que los estudiantes repasaran la morfología verbal y nominal (vid. Figura 2).

En segundo lugar, se propuso la elaboración de una wiki colaborativa en la misma platafor- 


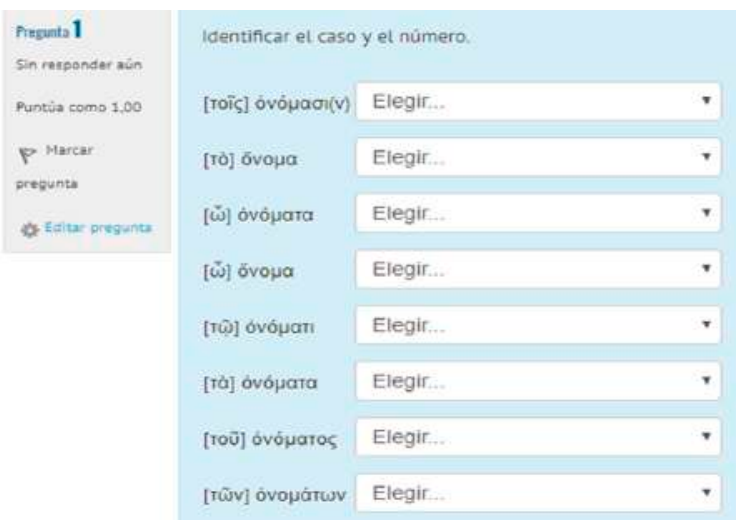

Figura 2. Cuestionario creado en Virtual Sabana para el repaso de la tercera declinación griega.

ma, en la que cada estudiante debía, no solo elegir un término griego, definirlo y explicarlo de acuerdo con su uso en la Metafísica, sino también revisar y comentar las entradas de sus compañeros. En este punto, la participación del grupo fue crucial para la retención del vocabulario. Por último, se enlazó un curso con la aplicación SuperMemo. Se trata de un software basado en la investigación de la memoria humana a largo plazo, las repeticiones espaciadas y la curva del olvido. Este software está disponible para cualquier dispositivo móvil con o sin conexión a internet. Su utilización en la enseñanza de lenguas es beneficiosa, pues ayuda al estudiante a desarrollar la competencia lexical y así lograr que las palabras aprendidas permanezcan en la memoria. Se recomienda usar SuperMemo mínimo tres minutos diarios, de manera que, como resultado, el software desarrolle algoritmos que permitan determinar el intervalo más efectivo en el cual una palabra puede ser recordada; estas repeticiones son conocidas como repeticiones espaciadas. Además, según el grado de dificultad, se aplica el principio de la curva del olvido, el cual está relacionado con la intensidad del recuerdo. La figura 3 representa la curva del olvido presenta cómo en unos días o semanas se olvida la mitad de lo aprendido, si no es repasado (vid. Figura 3) (Woźniak, 2018).

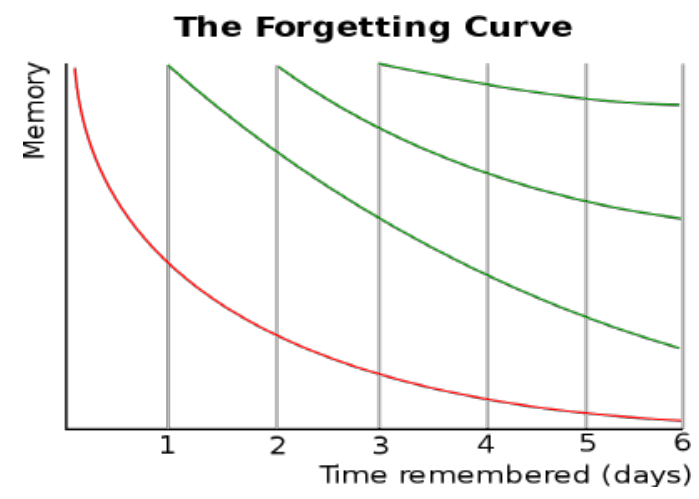

Figura 3. La curva del olvido. Imagen tomada de https://es.wikipedia.org/wiki/Curva_del_olvido\#/ media/File:ForgettingCurve.svg. Dominio público.

El uso de SuperMemo no presenta mayores dificultades. Primero, es necesario tener una cuenta, dar clic en 'crear un curso nuevo', darle un título y de inmediato será posible agregar el contenido que se desea aprender o enseñar. También, es posible modificar las propiedades del curso (el idioma, la descripción del mismo o el tipo de publicación — pública o privadaque se desea realizar). Otras opciones son la modificación, reorganización o eliminación del contenido. Recientemente es posible añadir en el curso imágenes, videos, música, animaciones, etc. Desde la perspectiva del estudiante, también resulta sencillo. Se debe descargar el software, crear una cuenta, iniciar sesión y buscar el curso que se desea realizar. Una vez iniciado, tendrá que responder las preguntas en la pantalla según el grado de dificultad que supongan para sí. De esta manera, los grados permitirán al programa reconocer con qué frecuencia la memoria necesita repetir cierta palabra en particular, según que tan bien o mal la pueda recordar. SuperMemo ofrece la opción de creación de MemoTarjetas, que consisten en una tarjeta diseñada por el estudiante según sus necesidades con la posibilidad de agregar frases célebres, imágenes, memes, gifs, audios, videos, etc. Una clave para garantizar la memorización de las palabras es la simplicidad en la organización del contenido, ya que así favo- 
rece la correcta sinapsis neuronal para mejorar la estimulación. Se debe tener en cuenta que la calidad del aprendizaje depende de la selección del material y la manera en que este es distribuido en piezas pequeñas y simples de conocimiento (Biedalak y Piotr, 2010, 2012).

Por otro lado, se enlazaron las siguientes herramientas para complementar el estudio independiente. Primero, se dejó a disposición de los estudiantes Le vocabulaire grec de la philosophie (Gobry, 2010) para la profundización del vocabulario filosófico. De igual manera, se facilitó el acceso mediante enlaces a la base de datos Thesaurus Linguae Graecae (TLG), el Diccionario didáctico interactivo griego - español (Dicciogriego), el Diccionario griego (DGE) y la página web Textkit, donde se encuentran gramáticas y otro tipo de textos para el estudio del griego clásico. Además, se crearon videos animados en la página web Go!Animate, ${ }^{10}$ los cuales contenían explicaciones de la gramática esencial para la lectura de la Metafisica (980a-982a), principalmente, morfosintácticas. Los videos fueron compartidos a través de YouTube, ${ }^{11}$ de modo que los estudiantes los visualizaran las veces que fueran necesarias para comprender las estructuras gramaticales. Finalmente, se crearon actividades y

10 Go! Animate es una página web que posibilita la creación de videos anim ados según las necesidades del usuario. Hay más alternativas para la edición, la carga, la publicación y la descarga con el pago de un monto mensual. En mayo del 2018, cambió la plataforma a Vyond (https://www.vyond.com/press/ goanimate-launches-vyond-brand/).

11 En el siguiente enlace, se pueden visualizar los videos creados para la explicación de la gramática básica https://www.youtube.com/channel/UCRL7yv2piZFjou3v_Q0elkQ/featured. Los contenidos gramaticales que se eligieron fueron las oraciones completivas de acusativo con infinitivo, la sustantivación por medio del artículo y las oraciones comparativas y superlativas. cuestionarios en plataformas como Kahoot!, Quizizz, EducaPlay y PurposeGames. ${ }^{12}$

Con respecto a las otras plataformas que se aplicaron, Kahoot! y Quizizz, se decidió implementar dinámicas de este tipo como una estrategia metodológica para aumentar la motivación, el input, el repaso de contenidos y el trabajo independiente. Esta técnica de aprendizaje toma el nombre de gamificación, la cual consiste en captar y mejorar la atención y la proactividad de los estudiantes usando las herramientas que la tecnología tiene a su disposición. La experiencia de los alumnos mejora al recibir un feedback y un ranking, ya que les permite repasar y recordar el contenido, conocer nueva información y los impulsa a estar en constante mejoramiento (García y Hijón, 2017). Presentamos a continuación las dos plataformas.

Kahoot! permite crear encuestas o pruebas de manera intuitiva (vid. Figura 4). ${ }^{13}$ Inicialmente, se debe crear una cuenta, para ello se elige un rol entre profesor o estudiante. Después, se da clic en 'crear un nuevo Kahoot!', ${ }^{14}$ se le asigna un nombre y una descripción. Una vez hecho esto, se pueden agregar las preguntas y

12 EducaPlay y PurposeGames son plataformas que permiten la creación de diversas actividades educativas. EducaPlay se utilizó para que los estudiantes completaran una oración según la palabra que correspondiera (https:/ / es.educaplay.com/es/recursoseducativos/3624785/los_cinco_sentidos.htm) y relacionaran las columnas (https://es.educaplay.com/es/recursoseducativos/3593354/los_cinco_sentidos.htm). Purpose Games se usó para crear dos juegos para enseñar el vocabulario en griego antiguo de las partes del cuerpo humano (https://www.purposegames.com/game/x6wI5 hJtYYW) y de las partes del rostro con la inclusión de un retrato de El Fayum (https://www.purposegames. com/game/1rya4YVUXd2).

13 El siguiente enlace da acceso al recurso: https://play. kahoot.it/\#/k/e665b614-591d-408c-ae55-9fe8921e34c5 14. La plataforma da la opción de crear una prueba, un jumble, una discusión o una encuesta. 


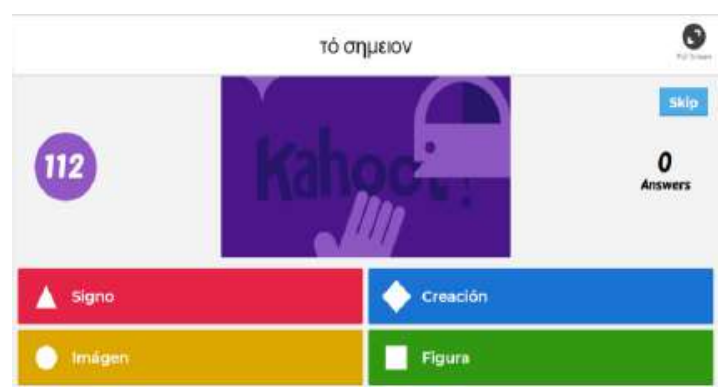

Figura 4. Captura de pantalla del cuestionario diseñado en Kahoot! para la práctica del vocabulario de la Metafísica. Elaboración propia.

las respuestas, editar el texto, añadir imágenes a la pregunta, modificar el tiempo límite de respuesta y seleccionar la respuesta correcta. Es necesario tener en cuenta que sigue el modelo de pregunta con opción múltiple. A continuación, se puede elegir el orden del cuestionario, el idioma y si será público o privado. La ventaja de que sea un Kahoot! de tipo privado es que la plataforma arroja una estadística detallada del grupo restringido que tuvo acceso. Para jugar, es necesario proyectar el Kahoot! creado, para que los jugadores se unan ingresando desde sus dispositivos con el código que visualizarán en la pantalla. Los estudiantes pueden responder de manera individual o grupal, según sea estipulado. Cada alumno debe elegir un pseudónimo con el que se identificará durante el juego. Se otorgarán puntos por las respuestas dadas correctamente y en el menor tiempo posible. Se presenta una puntuación al final de cada pregunta, lo cual funciona como un estímulo al estudiante para mejorar en cada pregunta y obtener la mejor posición en el ranking final (Furuseth y Versvik, 2018).

Quizizz fue elegida para reforzar no solo el vocabulario y las estructuras gramaticales, sino también para comprobar la comprensión y la interpretación del texto aristotélico, ya que las preguntas se crearon a partir del texto de la Metafisica en griego (vid. Figura 5). El funcionamiento de Quizizz es similar al de Kahoot! En

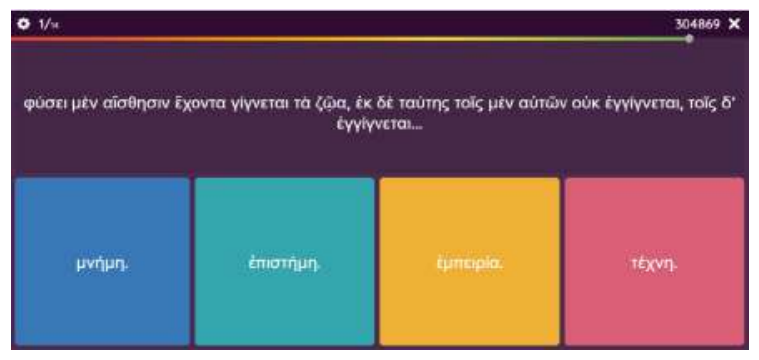

Figura 5. Captura de pantalla del cuestionario diseñado en Quizizz para reforzar el vocabulario, las estructuras gramaticales y comprobar la comprensión e interpretación del texto aristotélico. Elaboración propia.

Quizizz es necesario crear una cuenta, dar clic en 'crear un cuestionario', asignarle un nombre y una descripción a la prueba, seleccionar el grado de privacidad, introducir las preguntas con sus respectivas respuestas, seleccionar la respuesta correcta, modificar el tiempo límite de respuesta, añadir una imagen, etc. El estudiante puede ingresar al cuestionario con el código generado, agregar un pseudónimo y empezar a jugar (Shamil, 2018). Sin embargo, Quizizz, a diferencia de Kahoot!, no tiene un límite de caracteres para la formulación de preguntas o respuestas, y se puede definir la fecha de inicio y de finalización del cuestionario. Asimismo, incluye otras funciones como proyectar la pregunta también en el dispositivo móvil, añadir un avatar para cada estudiante e introducir imágenes divertidas que aparecen una vez se responde a la pregunta.

\subsubsection{Presentación, interpretación y traducción del texto origen}

El texto griego fue organizado y presentado en la aplicación OneNote ${ }^{\circledR}$, la cual forma parte de la plataforma Microsoft Teams ${ }^{\circledR}$. La aplicación fue implementada con el objetivo de apoyar e integrar el proceso de traducción, pues es un espacio donde el estudiante puede trabajar de forma colaborativa con el docente y sus compañeros. Primero se debe tener en 


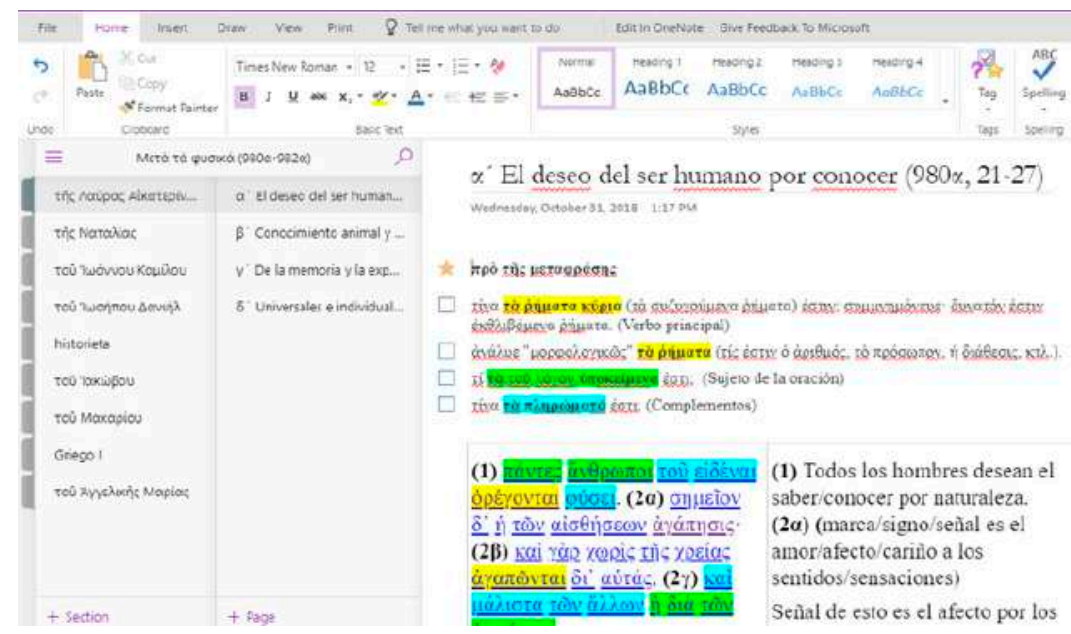

Figura 6. Captura de pantalla del proceso de traducción en OneNote de un estudiante. Elaboración propia.

cuenta que para utilizar OneNote ${ }^{\circledR}$ es necesario estar registrado en Outlook ${ }^{\circledR}$. OneNote ${ }^{\circledR}$ hace posible la creación y la edición de un bloc de notas personalizadas y permite, por un lado, la comunicación y la participación activa y, por otro, posibilita insertar un texto digital, imágenes, tablas, enlaces a páginas web, videos, audios, información y material complementario de la clase y de la lectura. La principal ventaja de OneNote ${ }^{\circledR}$ es la cantidad de opciones de edición, lo que es favorable para el aprendizaje al ser cómodo y estar disponible desde cualquier dispositivo portátil con acceso a internet (Marrandino, 2010).

Para la lectura de la introducción a la Metafisica de Aristóteles (980a-982a) se decidió crear una sección que reunía los blocs de notas del curso, en los que las instrucciones fueron dadas total o parcialmente en griego clásico para lograr ofrecer un mayor input lingüístico a los estudiantes (vid. Figura 6). Se les sugirieron pasos que debían seguir en el análisis del texto para proponer una buena traducción, como son el iniciar con la búsqueda del verbo principal, el análisis morfológico del mismo y la identificación del sujeto y los complementos del verbo, los cuales debían resaltarse con colores distintivos. Asimismo, OneNote permite el seguimiento del proceso, puesto que el profesor puede observar, analizar y evaluar el proceso de traducción que lleva cada estudiante. De esta manera, el docente accede a las distintas pestañas de los estudiantes y la propia para hacer anotaciones, aclaraciones, correcciones, etc. Esta plataforma fue elegida porque se puede enlazar el diccionario griego Liddell-Scott-Jones (LSJ) a través de Greek Word Study Tool una herramienta de Perseus Digital Project (Crane, 2018). Así, al hacer clic sobre una palabra se abre la entrada al LSJ en Perseus. La presentación y organización del texto origen fue dividida en seis partes, siguiendo la propuesta por Cambiano en su artículo "The Desire to Know" (2013). ${ }^{15}$

Como se mencionó, Perseus Digital Project fue uno de los recursos elegidos para la interpretación, el análisis y la traducción del texto origen. Perseus es un proyecto que ha desarrollado una biblioteca digital que reúne diferentes recursos como textos en diferentes idiomas, traduccio-

$15 \mathrm{El}$ artículo forma parte de los trabajos introductorios de la más reciente edición del primer libro de la Metafisica (Steel y Primavesi, 2013). 


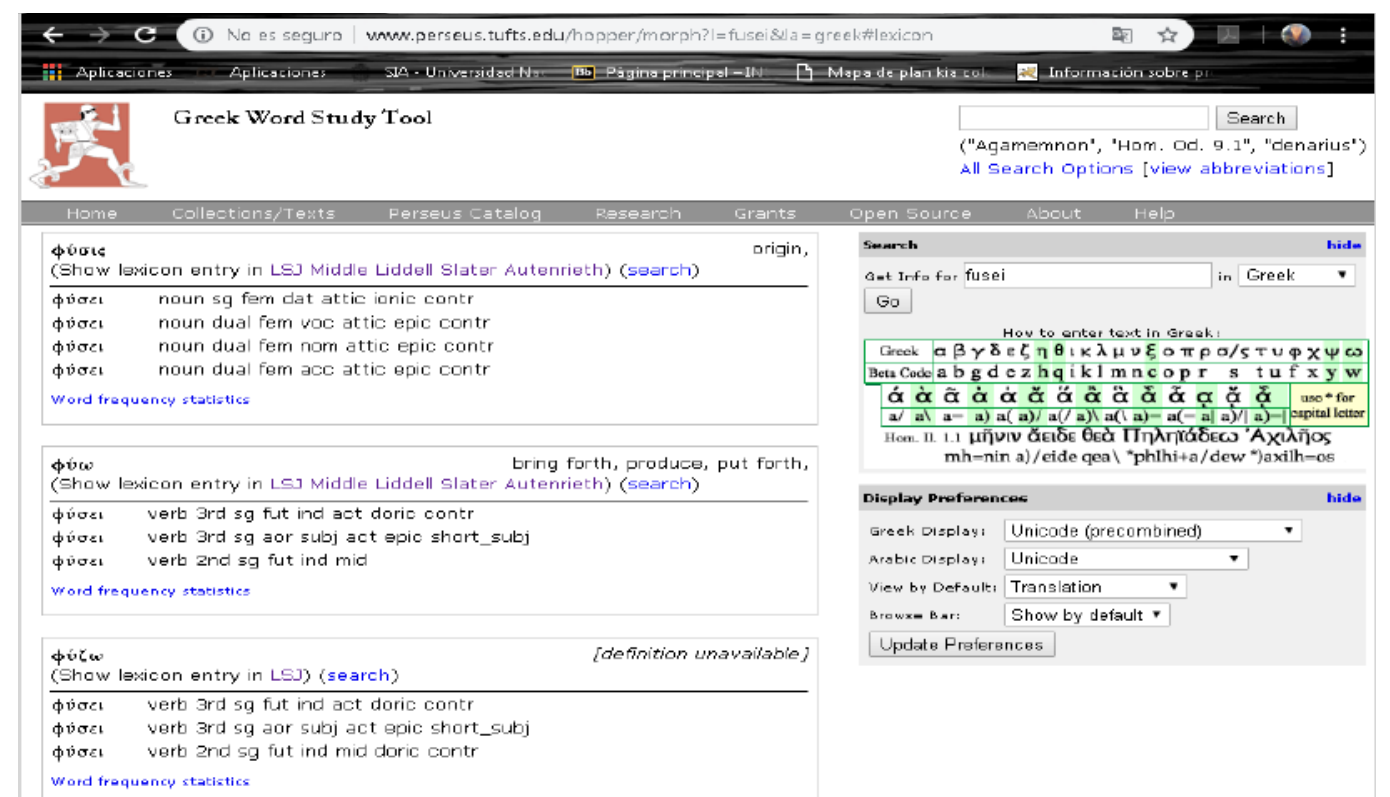

Figura 7. Captura de pantalla de Perseus Digital Project en la cual se presenta el análisis morfológico de la palabra griega фúఠદı. Dominio común.

nes, vasijas, pinturas, etc. Actualmente la investigación de Perseus Digital Project se centra en el efecto que tienen las interconexiones entre textos, comentarios, gramáticas, diccionarios y otras herramientas de referencia sobre la experiencia de la lectura y la traducción (Crane, 2018). Perseus es de las pocas herramientas digitales que cuenta con el análisis lingüístico y lexical, lo cual permite y facilita la lectura de textos antiguos (vid. Figura 7). Para usar este recurso, se debe ingresar a Perseus Digital Project y dirigirse a Greek Word Study Tool. Una vez en esta página, se debe elegir la lengua que se va a trabajar e ingresar la palabra a analizar. Para griego clásico, Perseus ofrece la opción de introducir el texto con el alfabeto griego o con el alfabeto latino siguiendo una tabla de equivalencias. Como resultado de la búsqueda, se pueden conseguir uno o más resultados que incluyen el análisis morfológico de la palabra y sus posibles equivalentes en la lengua inglesa; la elección de la entrada dependerá del objetivo de estudio. Es posible profundizar en la se- mántica de la palabra griega dando clic sobre el diccionario Liddel-Scott-Jones (LSJ). Este diccionario presenta las variedades dialectales de la palabra y los posibles significados citando brevemente pasajes de autores clásicos donde se encuentra con mayor o menor frecuencia el uso específico según el contexto.

\section{Sistema de evaluación}

El proceso de evaluación se realizó por medio de un sistema de $e$-rúbricas analíticas que comprendió tres etapas: autoevaluación, coevaluación entre los alumnos de la asignatura y evaluación por parte del docente. El objetivo de formalizar la evaluación de esta manera se debió a que se siguieron los principios de la evaluación formativa, en la medida en que se aprovechó cada uno de los momentos no solo para reforzar y repasar los contenidos vistos en clase, sino también para sensibilizar a los estudiantes sobre su proceso de aprendizaje, hacer un seguimiento de dicho proceso, realizar ajustes en el desarrollo de la clase y 

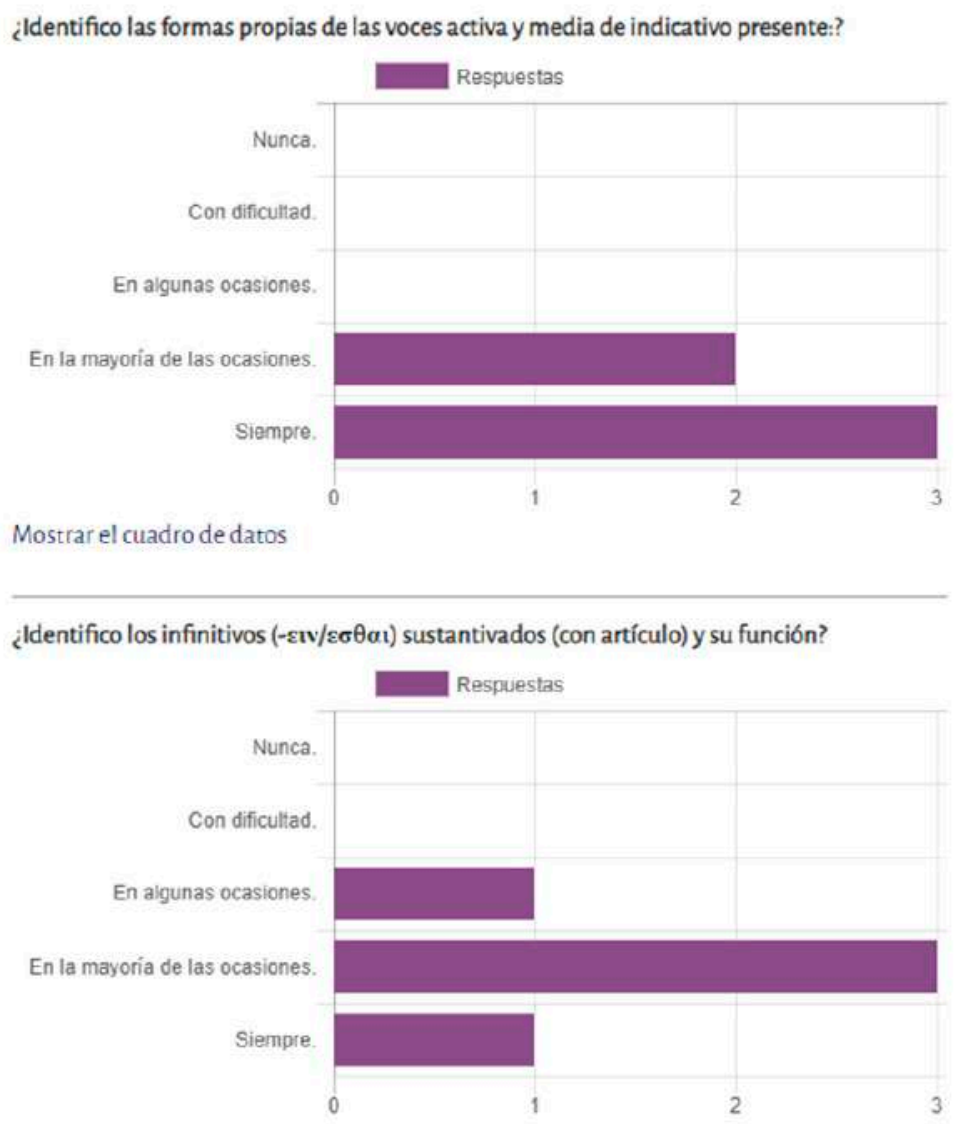

Figura 8. Ejemplos de resultados de la autoevaluación de los estudiantes en el curso de Griego II.

ofrecer alternativas a los estudiantes para superar sus dificultades. ${ }^{16} \mathrm{La}$ autoevaluación se llevó a cabo en Virtual Sabana a través de la actividad 'Encuesta', en la que cada pregunta correspondió a un criterio gramatical visto en clase relacionado con la comprensión lingüística del texto origen. Así, cada estudiante podía hacer un diagnóstico que le permitiera reforzar los contenidos de difícil comprensión, bien sea con estudio autónomo o con la ayuda

16 Este sistema de evaluación de lenguas clásicas en la Universidad de La Sabana se empezó a diseñar e implementar desde 2017. El sistema que se describe en este artículo es una adaptación para efectos de la enseñanza de la traducción. Cfr. Forero Álvarez (2018). Sobre la evaluación formativa, cfr. Buscà, Pintor, Martínez y Peire (2010); Fluckiger, Vigil, Pasco y Danielson (2010). del docente o de los compañeros de clase. La autoevaluación constó de los siguientes ítems que se exponen en el Apéndice 1.

La elección de Virtual Sabana para este proceso se debió a que genera gráficos y permite extraer datos sobre la percepción que tienen los estudiantes sobre su proceso de aprendizaje, de manera que el docente puede conocer con antelación las dificultades de los estudiantes y crear una actividad de repaso específica antes del parcial (vid. Figura 8).

La coevaluación se realizó en el salón durante la corrección de un taller de repaso, que debía realizarse antes de la penúltima clase previa al parcial. Este consistió en completar un 
cuadro de vocabulario y realizar la traducción de oraciones de español a griego y de griego a español, tomadas con modificaciones de la Metafisica. El ejercicio de la coevaluación tenía como objetivos los mismos de la autoevaluación y el de fomentar el trabajo cooperativo (Gessa Perera, 2011; Sluijsmans, Dochy y Moerkerke, 1998). Como en los dos cortes anteriores, el proceso constó de dos rúbricas, una para evaluar los contenidos gramaticales, la otra para el texto meta. La primera consistió en un impreso que solo difería de la rúbrica de autoevaluación en la formulación de las preguntas de manera que permitiera que un alumno evaluara al otro a partir de la corrección del taller en clase, i. e., 'ha memorizado', 'identifica', 'reconoce', etc. La segunda incluyó los criterios de evaluación de la traducción que se iban a tener en cuenta, los cuales tienen en cuenta las competencias específicas de traducción descritas más arriba (vid. sección 1.2.3). Los criterios se dividieron en:

1) léxico (equivalencias),

2) transferencia de las ideas del texto origen (omisiones, adiciones, divergencias, calcos, hipérbaton),

3) redacción (coherencia, cohesión, adecuación y claridad) y

4) forma (ortografía, acentuación, puntuación y caligrafía).

La rúbrica se implementó desde los dos cortes anteriores en el ejercicio de coevaluación, con el fin de que los estudiantes se familiarizaran con los conceptos propios de la traducción y fueran más conscientes durante el proceso. Estos criterios fueron redactados en los descriptores en un lenguaje sencillo y comprensible para los alumnos. La rúbrica que se presenta en la tabla 4 fue entregada impresa y los criterios fueron explicados de nuevo y de manera detallada antes de iniciar la corrección del taller.

La evaluación de la prueba escrita ${ }^{17}$ por parte del profesor se realizó en una hoja de cálculo en Google Drive ${ }^{\circledR}$. Se usaron las dos rúbricas, donde se asignó un $50 \%$ de la nota a la comprensión lingüística del texto origen y otro $50 \%$ a la presentación del texto meta. Se eligió esta plataforma, porque permite formular los criterios para sacar las notas fácilmente y obtener datos no solo de un alumno en particular, sino del curso en general. También ofrece al estudiante una retroalimentación personalizada y le permite comparar su rendimiento con el de los cortes anteriores, con el de los demás compañeros ${ }^{18}$ y con el del curso. La publicación de las notas se hace en Virtual Sabana, aunque también se puede hacer por correo electrónico, pues la hoja de cálculo proporciona un enlace que cualquier persona puede consultar (vid. Figuras 9 a y b).

17 Consistió en un cuadro de vocabulario, la traducción de tres oraciones del español al griego y un fragmento de la introducción del texto visto en clase al que se le cambió ligeramente el orden de las palabras para facilitar la comprensión por parte de los estudiantes, pues la prueba escrita se hace sin diccionario ni gramática, pero con la opción de preguntarle al profesor el significado de tres palabras para disminuir la ansiedad.

18 Cada estudiante tiene una hoja con un código que solo él conoce, por lo que, aunque los resultados son públicos, la identidad de los estudiantes no es revelada. 
Tabla 4. Rúbrica de evaluación

\begin{tabular}{|c|c|c|c|c|c|}
\hline \multicolumn{6}{|c|}{ Interpretación y traducción del texto griego } \\
\hline & \multicolumn{5}{|c|}{ Vocabulario } \\
\hline & \multicolumn{5}{|c|}{ Encuentra equivalentes en español de palabras y expresiones griegas: } \\
\hline $\begin{array}{l}\text { ถ̊ } \\
\text { है }\end{array}$ & $\begin{array}{l}\text { En pocas } \\
\text { ocasiones (1) }\end{array}$ & $\begin{array}{l}\text { En algunas } \\
\text { ocasiones (2) }\end{array}$ & $\begin{array}{l}\text { En muchas } \\
\text { ocasiones (3) }\end{array}$ & $\begin{array}{l}\text { En la mayoría de } \\
\text { las ocasiones (4) }\end{array}$ & Siempre (5) \\
\hline 艾 & & & & & 5 \\
\hline
\end{tabular}

\begin{tabular}{|c|c|c|c|c|c|}
\hline & \multicolumn{5}{|c|}{ OMISIONES } \\
\hline & \multicolumn{5}{|c|}{ La traducción presenta omisiones importantes que perjudican la transmisión de las ideas del texto griego: } \\
\hline & \multirow[t]{2}{*}{$\begin{array}{l}\text { En la mayoría de } \\
\text { las ocasiones (1) }\end{array}$} & $\begin{array}{l}\text { En muchas } \\
\text { ocasiones (2) }\end{array}$ & $\begin{array}{l}\text { En algunas } \\
\text { ocasiones (3) }\end{array}$ & $\begin{array}{l}\text { En pocas } \\
\text { ocasiones (4) }\end{array}$ & $\begin{array}{l}\text { No presenta } \\
\text { omisiones } \\
\text { importantes (5) }\end{array}$ \\
\hline & & & & & 5 \\
\hline & \multicolumn{5}{|l|}{ Adiciones } \\
\hline & \multicolumn{5}{|c|}{$\begin{array}{l}\text { La traducción presenta adiciones innecesarias que interfieren en la transmisión de las ideas del texto } \\
\text { griego: }\end{array}$} \\
\hline & \multirow[t]{2}{*}{$\begin{array}{l}\text { En la mayoría de } \\
\text { las ocasiones (1) }\end{array}$} & $\begin{array}{l}\text { En muchas } \\
\text { ocasiones (2) }\end{array}$ & $\begin{array}{l}\text { En algunas } \\
\text { ocasiones (3) }\end{array}$ & $\begin{array}{l}\text { En pocas } \\
\text { ocasiones (4) }\end{array}$ & $\begin{array}{l}\text { No presenta } \\
\text { adiciones } \\
\text { innecesarias (5) }\end{array}$ \\
\hline & & & & & 5 \\
\hline & \multicolumn{5}{|l|}{ Divergencias } \\
\hline & \multicolumn{5}{|c|}{ Las ideas que se encuentran en la traducción son diferentes a las que se encuentran en el texto griego: } \\
\hline & \multirow[t]{2}{*}{$\begin{array}{l}\text { En la mayoría de } \\
\text { las ocasiones (1) }\end{array}$} & $\begin{array}{l}\text { En muchas } \\
\text { ocasiones (2) }\end{array}$ & $\begin{array}{l}\text { En algunas } \\
\text { ocasiones (3) }\end{array}$ & $\begin{array}{l}\text { En pocas } \\
\text { ocasiones (4) }\end{array}$ & $\begin{array}{l}\text { No presenta } \\
\text { divergencias (5) }\end{array}$ \\
\hline & & & & & 5 \\
\hline தீ음 & \multicolumn{5}{|l|}{ Calcos } \\
\hline$\stackrel{\circ}{\circ}$ & \multicolumn{5}{|c|}{$\begin{array}{l}\text { La copia de estructuras gramaticales y/o léxicas del griego ajenas a las del español lleva a que la } \\
\text { traducción contenga errores gramaticales y/o no se comprenda el texto: }\end{array}$} \\
\hline $\begin{array}{l}0 \\
\frac{0}{x} \\
\stackrel{0}{ \pm}\end{array}$ & $\begin{array}{l}\text { En la mayoría de } \\
\text { las ocasiones (1) }\end{array}$ & $\begin{array}{l}\text { En muchas } \\
\text { ocasiones (2) }\end{array}$ & $\begin{array}{l}\text { En algunas } \\
\text { ocasiones (3) }\end{array}$ & $\begin{array}{l}\text { En pocas } \\
\text { ocasiones (4) }\end{array}$ & $\begin{array}{l}\text { No presenta } \\
\text { calcos (5) }\end{array}$ \\
\hline $\begin{array}{l}\tilde{y} \\
\tilde{y}\end{array}$ & & & & & 5 \\
\hline$\frac{0}{n}$ & \multicolumn{5}{|l|}{ Hipérbaton } \\
\hline $\begin{array}{l}\frac{1}{0} \\
\frac{0}{0} \\
0\end{array}$ & \multicolumn{5}{|c|}{$\begin{array}{l}\text { El orden de las palabras de la traducción dificulta su comprensión debido a que intenta conservar siempre } \\
\text { el mismo orden del texto griego: }\end{array}$} \\
\hline$\frac{\frac{c}{0}}{\frac{1}{d}}$ & $\begin{array}{l}\text { En la mayoría de } \\
\text { las ocasiones (1) }\end{array}$ & $\begin{array}{l}\text { En muchas } \\
\text { ocasiones (2) }\end{array}$ & $\begin{array}{l}\text { En algunas } \\
\text { ocasiones (3) }\end{array}$ & $\begin{array}{l}\text { En pocas } \\
\text { ocasiones (4) }\end{array}$ & $\begin{array}{l}\text { No presenta } \\
\text { hipérbaton (5) }\end{array}$ \\
\hline$\stackrel{0}{\triangleq}$ & & & & & 5 \\
\hline
\end{tabular}




\begin{tabular}{|c|c|c|c|c|c|}
\hline & \multicolumn{5}{|c|}{ Coherencia, cohesión, adecuación y claridad } \\
\hline bo & \multicolumn{5}{|c|}{$\begin{array}{l}\text { La redacción de la traducción presenta incoherencias, falta de cohesión, problemas de adecuación y/c } \\
\text { poca claridad: }\end{array}$} \\
\hline \multirow{2}{*}{ 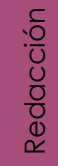 } & $\begin{array}{l}\text { En la mayoría de } \\
\text { las ocasiones (1) }\end{array}$ & $\begin{array}{l}\text { En muchas } \\
\text { ocasiones (2) }\end{array}$ & $\begin{array}{l}\text { En algunas } \\
\text { ocasiones (3) }\end{array}$ & $\begin{array}{l}\text { En pocas } \\
\text { ocasiones (4) }\end{array}$ & $\begin{array}{l}\text { El texto no } \\
\text { presenta errores } \\
\text { de redacción (5) }\end{array}$ \\
\hline & & & & & 5 \\
\hline
\end{tabular}

\section{Ortografía, acentuación, puntuación y caligrafía}

La traducción presenta errores de ortografía, acentuación y/o puntuación y/o una letra difícil de leer:

\begin{tabular}{|l|l|l|l|l|}
\hline $\begin{array}{l}\text { En la mayoría de } \\
\text { las ocasiones (1) }\end{array}$ & $\begin{array}{l}\text { En muchas } \\
\text { ocasiones (2) }\end{array}$ & $\begin{array}{l}\text { En algunas } \\
\text { ocasiones (3) }\end{array}$ & $\begin{array}{l}\text { En pocas } \\
\text { ocasiones (4) }\end{array}$ & $\begin{array}{l}\text { El texto no } \\
\text { presenta faltas } \\
\text { formales (5) }\end{array}$ \\
\hline & & & & 5 \\
\hline
\end{tabular}

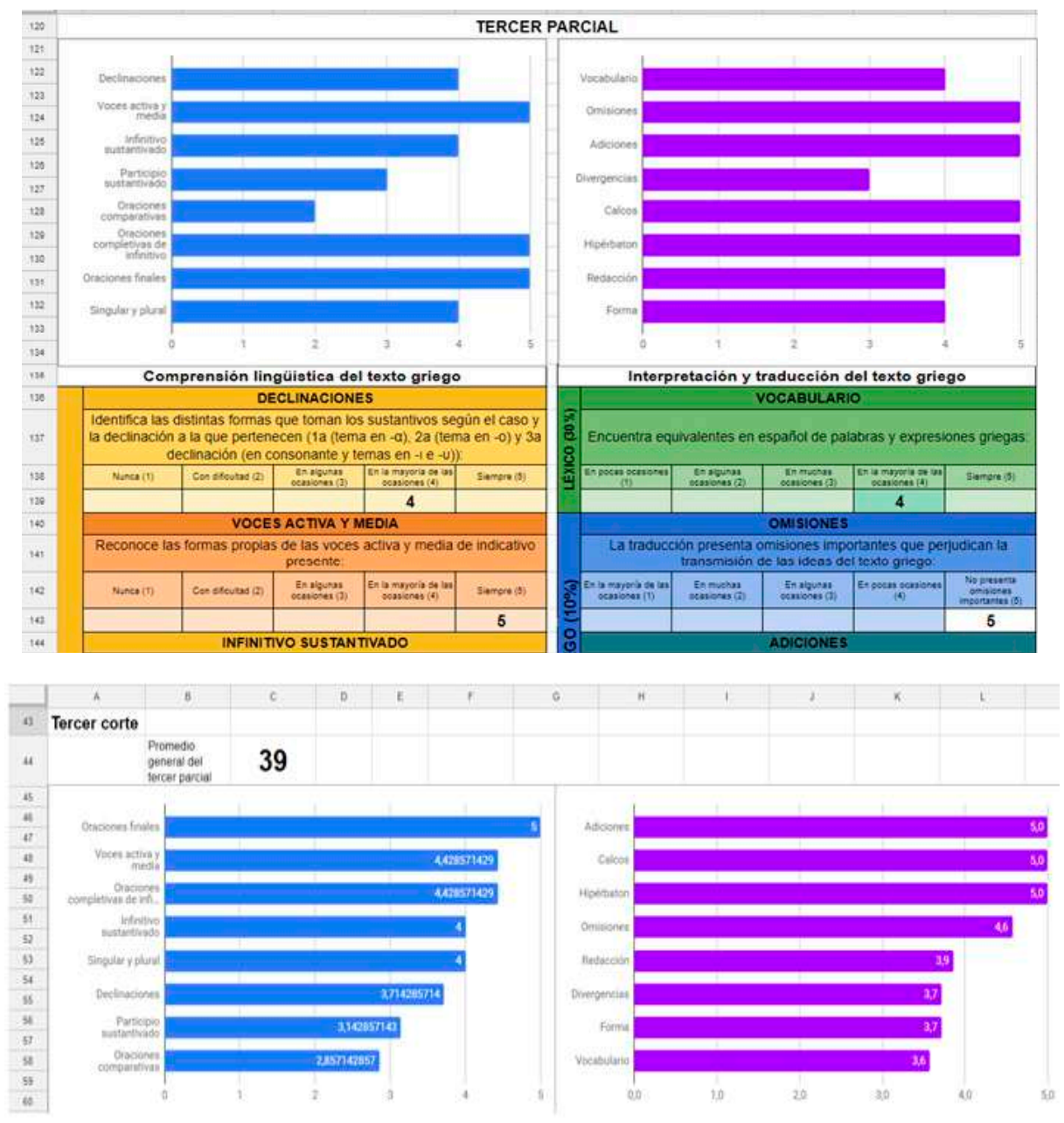

Figuras 9 a y b. Capturas de pantalla de los resultados obtenidos de la prueba final escrita del curso de Griego ॥ en el tercer corte. Elaboración propia. 


\section{Conclusiones}

Como conclusiones, presentamos la tercera etapa de la investigación-acción (interés emancipatorio), para la cual se usaron una encuesta anónima en Google Drive ${ }^{\circledR}$ dirigida a los estudiantes y un diario de campo del profesor, que permitieron conocer la opinión del alumnado durante el proceso de aprendizaje y observar los resultados de la implementación de la unidad.

El objetivo de la encuesta era que el curso evaluara la transformación de la práctica pedagógica, la implementación de las TAC y la evaluación con e-rúbricas analíticas. Las preguntas fueron de opción múltiple con la posibilidad de hacer comentarios y sugerencias. Los resultados de la encuesta indican el éxito de la unidad, tal como puede apreciarse en el Apéndice 2. Además del impacto positivo que revelan los gráficos y las respuestas, los estudiantes manifiestan que la unidad facilitó el aprendizaje y transformó la didáctica de las clases. De las nuevas actividades, resaltaron el aprendizaje del vocabulario en SuperMemo por su notable aporte a la memorización, uno de los aspectos más difíciles en el aprendizaje de las lenguas clásicas. Los videos fueron apreciados por su creatividad y efectividad. En cuanto a la presentación del texto en OneNote $^{\circledR}$, se destacaron la organización y la utilidad de los enlaces a Perseus Digital Project, de manera que permitieron una consulta expedita del diccionario. El sistema de evaluación cumplió con su objetivo de sensibilizar a los estudiantes con su proceso de aprendizaje y de servirles de guía. Como aspectos por mejorar, los estudiantes recomendaron mejorar la calidad del audio, la duración y la inclusión de más ejemplos en los videos. También fueron señalados los problemas técnicos con OneNote ${ }^{\circledR}$, debido a que, en algunos casos, los cambios no se guardan convenientemente en el archivo por problemas de conectividad.

De las observaciones consignadas en el diario de campo — sintetizadas a continuación-, resaltan la emoción y la satisfacción de los estudiantes cuando expusieron en clase sus traducciones por primera vez, pues comentaron que se les había facilitado en gran medida la preparación del texto meta. De hecho, algunos manifestaron su interés en continuar con el estudio de la Metafisica el siguiente semestre y propusieron la creación de una electiva de Griego III. ${ }^{19}$ Por otro lado, la transformación de la práctica pedagógica favoreció el mejoramiento del ambiente en el aula, ya que contar con actividades desde distintos enfoques de enseñanza-aprendizaje y dejar varias de las explicaciones gramaticales como trabajo independiente le dio dinamismo a la clase y permitió centrarse en las dificultades de los estudiantes. Con el estudio autónomo de los contenidos gramaticales y del vocabulario, cada estudiante pudo trabajar a su ritmo y enfocar el trabajo en el aula en el desarrollo de las competencias de traducción. La implementación de las TAC en el curso resultó crucial en la transformación de la asignatura, debido a que facilitó la orientación del profesor y ayudó a comprender las necesidades de los estudiantes a través de la $e$-evaluación. Las TAC facilitaron la orientación del profesor durante todo el proceso, pues fueron fundamentales sus comentarios y la disponibilidad de una versión del texto meta construida entre todos, como quedó consignada en el archivo.

El reto de abordar un texto filosófico también lo fue para el docente, pues tuvo que enfocar su

19 En respuesta a la petición, se propuso a los estudiantes la creación de la electiva 'Textos filosóficos antiguos', la cual se espera ofrecer en el segundo semestre de 2019. 
clase en el desarrollo de competencias de traducción, objetivo nada fácil, pero al que contribuyó decisivamente la rúbrica de traducción, ya que le permitió al docente tener claridad sobre qué debía enseñar en el aula. Gracias a ello, se enseñaron aspectos que antes no se tenían en cuenta o a los que se prestaba poca atención, pero que afectan el texto meta. Tal es el caso del hipérbaton, los calcos y los aspectos de forma y de redacción. Gracias a este énfasis, ahora las traducciones son más fáciles de entender y evaluar, lo que permite al docente centrarse en otros aspectos más importantes, como las divergencias.

Por otra parte, la insistencia en encontrar equivalentes permitió a los estudiantes comprender mejor el texto origen y no centrarse en encontrar una palabra exacta, sino ser conscientes de la posibilidad de traducir usando más palabras, de manera que el texto transmitiera la idea. Tal es caso de aísthesis que, dependiendo del contexto, podría traducirse como 'facultad de sentir', 'acto de sentir' o 'percepción sensorial', pues las acepciones de 'sensación' y de 'sentido' (pl. 'sentidos') no siempre ayudan a comprender con exactitud los postulados aristotélicos. Del mismo modo, la palabra tékhne, que en muchas ocasiones es traducida por 'arte' o 'técnica', en el caso de la introducción de la $\mathrm{Me}$ tafisica queda mejor entendida por 'habilidad o saber orientado a la producción, capacidad de producción, etc.', en contraste con epistéme, 'saber teorético', orientado al conocimiento y no a la producción. Este trabajo es una habilidad fundamental para la interpretación de textos filosóficos, en los cuales es más importante comprender el concepto y los contextos en los que una palabra aparece que encontrar un único equivalente. En el plano sintáctico, la búsqueda de equivalencias también presentó retos, debido a que el estagirita usa continuamente la sustantivación por medio del artículo que en casos como tò kathólu y tò kath' hékaston deben enten- derse por 'lo general' y 'lo particular', cuya formación del sintagma mediante los artículos y el adverbio y el adjetivo no es común en lengua española. El hipérbaton, por su parte, debió ser tenido en cuenta en la medida en que el orden difiere en muchos casos al del español, pues el filósofo ordena las palabras atendiendo a sus intereses argumentativos y estilísticos, por lo que no siempre puede dejarse el mismo orden del original griego. En el caso de los periodos extensos y complejos sintácticamente, el uso de OneNote ${ }^{\circledR}$ favoreció enormemente la labor de traducción, ya que permitió dividir el texto en unidades de sentido más breves y reconocer su estructura por medio de los colores con los que se iban resaltando ambos textos (cfr. 2.1.2.).

Dado que estas explicaciones son fundamentales, el profesor considera ahora indispensable hacer estos énfasis desde el primer nivel de lengua para que los estudiantes los tengan en cuenta y más que una transposición de palabras, construyan un texto comprensible que transmita las ideas del texto origen. Esta instrucción ya se está ofreciendo en todos los cursos, con excelentes resultados, de manera que se nota el cambio en la presentación de los textos meta. También se le ha hecho énfasis al alumnado en que los contenidos de traducción pueden aplicarse a otras lenguas y se han puesto ejemplos, especialmente del inglés, de manera que sean más conscientes a la hora de traducir, no solo griego, sino cualquier otra lengua, solucionando problemas de interpretación y siendo más conscientes de las diferencias entre las lenguas en todos los aspectos (gramatical, semántico, etc.). Asimismo, incluir y evaluar los aspectos de la traducción enriquece y hace más conscientes los procesos en el aula, gracias a los nuevos criterios.

Finalmente, puede observarse cómo la opinión de los estudiantes resulta fundamental para la transformación y el mejoramiento de 
las clases. Las sugerencias y las recomendaciones dadas por los alumnos son valiosas y constituyen el punto de partida desde el cual el profesor debe reflexionar para modificar y actualizar su práctica pedagógica, porque la perspectiva que tienen ellos sobre el curso es diferente a la del docente y ayuda a enriquecer la planeación de actividades del curso dentro y fuera del aula. Por otra parte, la efectividad de las TAC se debe a la elección y organización de los contenidos, siguiendo criterios rigurosos. El desarrollo de este tipo de unidades dedicadas a la traducción e interpretación -no solo de textos antiguos, sino de cualquier otra lengua - resulta un aporte, puesto que su impacto en la docencia y el aprendizaje es notablemente significativo.

\section{Referencias}

Balme, M., Lawwal, G. y Morwood, J. (1990). Athenaze: An intoduction to ancient Greek. Oxford: Oxford University Press. Recuperado de http://www.vroma.org/ abarker/ tsintro.html

Balme, M. y Morwood, J. (2006). Oxford Latin Course. Reino Unido: Oxford University Press.

Beeby, A. (2000). Evaluating the Development of Translation Competence. En B. J. Adab y C. Schäffner (eds.), Developing Translation Competence (pp. 185-198). Amsterdam: John Benjamins Publishing Co.

Beetham, F. (2017). Learning Greek with Plato. A Beginner's Course in Classical Greek. Exeter: University of Exeter Press.

Biedalak, K. y Piotr, W. (2010). Build your vocabulary with SuperMemo. Recuperado de https://www.supermemo.com/articles/ spotl.htm

Biedalak, K. y Piotr, W. (2012). General Principles of the SuperMemo Method. Recuperado de https://www.supermemo.com/archive/sm8help/sm89zso.htm

Bonilla Carvajal, C. A. (2013). Método "traducción gramatical", Un histórico error lingüístico de perspectiva: Orígenes, dinámicas einconsistencias. Praxis \& Saber, 4(8), 243-263. doi: 10.19053/22160159.2660

Buscà, F., Pintor, P., Martínez, L. y Peire, T. (2010). Sistemas y procedimientos de Evaluación Formativa en docencia universitaria: Resultados de 34 casos aplicados durante el curso académico 2007-2008. Estudios Sobre Educación, (18), 255-276.

Cambiano, G. (2013). The Desire to Know. En Aristotle's Metaphysics Alpha (pp. 1-42). Oxford: Oxford University Press.

Carbonell, S. (2010). La crisis del griego antiguo y los métodos antidepresivos. Estudios Clásicos, 137, 85-95.

Carbonell, S. (2014). АІААОГОГ: prácticas de griego antiguo. España: Editorial Cultural Clásica.

Cohen, S. (2016). Aristotle's Metaphysics. Recuperado de https://plato.stanford.edu/ entries/aristotle-metaphysics/

Crane, G. (1998, enero). The Perseus Project and beyond: How building a Digital Library challenges the Humanities and Technology. D-Lib Magazine. The Magazine of Digital Library Research, 4(1), [html]. Recuperado de http://www.dlib.org/dlib/ january98/01crane.html

Crane, G. (2018). Perseus Digital Library Project. Recuperado de http://www.perseus.tufts. edu/hopper/

Donini, P. (2014). La Metafisica di Aristotele, introduzione alla lettura ( $3^{\text {a }}$ edición). Roma: Carocci editore.

Dussel, I. (2009). Entrevista con Nicholas Mirzoeff. La cultura visual contemporánea: 
política y pedagogía para este tiempo. Propuesta Educativa, (31), 69-79.

Fluckiger, J., Vigil, Y., Pasco, R. y Danielson, K. (2010). Formative Feedback: Involving Students as Partners in Assessment to Enhance Learning. College Teaching, 58(4), 136-140. doi:10.1080/87567555.2010.484 031

Fobes, F. H. (1957). Philosophical Greek: An Introduction. Chicago: The University of Chicago Press.

Forero Álvarez, R. (2018). El sistema de evaluación de lenguas clásicas en la Universidad de La Sabana. Evaluar para aprender (pp. 105128). Bogotá: Universidad de La Sabana.

Furuseth, A. y Versvik, M. (2018). What is Kahoot!? Recuperado de https://kahoot. com/what-is-kahoot/

García, M. y Hijón, R. (2017). Análisis para la gamificación de un curso de Formación Profesional. Revista Iberoamericana de Informática Educativa, (26), 46-60.

Gessa Perera, A. (2011). La coevaluación como metodología complementaria de la evaluación del aprendizaje. Análisis y reflexión en las aulas universitarias. Revista de Educación, (354), 749-764.

Gobry, I. (2010). Le vocabulaire grec de la philosophie. París: Ellipses.

Grondin, J. (2014). Capítulo III: Aristóteles, los horizontes de la filosofía primera. En E. Herder (ed.), Introducción a la Metafisica. Recuperado de http://reader. digitalbooks.pro/book/preview/28161/ c3?1525226330858

Hardwick, L. (2000). Translating Words, Translating Cultures. Londres: Duckworth.

Horneffer, R. (2008). Aristóteles: La metafisica como la ciencia de los hombres li- bres. Claves Del Pensamiento, 2(4), 91-99.

Recuperado de http://www.scielo.org. $\mathrm{mx} /$ scielo.php?script $=$ sci_arttext $\&$ pi$\mathrm{d}=$ S1870-879X2008000200005\&lng=es\&t$\operatorname{lng}=\mathrm{es}$

Hurtado, A. (1994). Perspectivas de los estudios sobre la traducción. Estudis Sobre La Traducció, 1, 25-41.

Hurtado, A. (1995). La didáctica de la traducción. Evolución y estado actual. En P. Fernández y J. Bravo (eds.), Perspectivas de la traducción (pp. 49-74). Valladolid: Universidad de Valladolid.

Jordan, R. (2000). Lo mejor de cada mundo: construyendo un principio ecléctico de currículo para personas con autismo. En x Congreso Nacional de Autismo (pp. 1-11). España.

Kelly, D. (2000). Text Selection for Developing Translator Competence: Why Texts From The Tourist Sector Constitute Suitable Material. En B. J. Adab y C. Schäffner (eds.), Developing Translation Competence (pp. 157-167). Amsterdam: John Benjamins Publishing Co.

Kemmis, S. y MacTaggart, R. (1988). Cómo planificar la investigación-acción. Barcelona: Laertes.

Kim, M. (2009). Meaning-oriented assessment of translations. En H. E. Jacobson y C. Angelelli (eds.), Testing and Assessment in Translation and Interpreting Studies: A Call for Dialogue Between Research and Practice (pp. 123-157). Amsterdam: John Benjamins Publishing Co.

Krashen, S. (1982). Principles and Practice in Second Language Acquisition. Oxford: Pergamon Press.

Lerís, D., Vea, F. y Velamazán, Á. (2015). Aprendizaje adaptativo en Moodle: tres casos prácticos. Education in the Know- 
ledge Society (EKS), 16(4), 138-157. doi: $10.14201 /$ eks 201516138157

Lewin, K. (1946). Action Research and Minority Problems. Journal of Social Issues, 2(4), 34-46.

Lowell, J. y Verleger, M. A. (2013). The Flipped Classroom: A Survey of the Research. En Proccedings of the Annual Conference of the American Society for Engineering Education. 120 th ASEE Annual Conference \& Exposition. Atlanta.

Marrandino, A. (2010). Poli Notes: un software di supporto al processo d'annotazione e all'aprendimento multimediale. Milán: Politecnico di Milano.

Martínez, C. (2008). Didáctica de las lenguas clásicas. Recuperado de http://www.culturaclasica.com/?q=node $\% 2 \mathrm{~F} 1918$

Martínez Miguélez, M. (2000). La investigación-acción en el aula. Agenda Académica, 7(1), 27-39.

Munday, A.D. y Peckett, C. W. (2009).

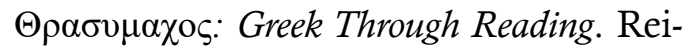
no Unido: Bristol Classical Press.

Ørberg, H. H. (1991). Lingua Latina per se Illvstrata, Pars i: Familia Romana. Grenaa: Domus Latina Editorial.

Praveen, C. (2013). The Eclectic Method - Theory and Its Application to the Learning of English. International Journal of Scientific and Research Publications, 3(6), 1-4.

Reeve, C. (2000). Substantial Knowledge, Aristotle's Metaphysics. Estados Unidos: Hackett Publishing Company.

Restrepo Gómez, B. (2009). Investigación de aula: formas y actores. Revista Educación y Pedagogía, 21(53), 103-112.

Richards, J. y Rodgers, T. S. (2001). Approaches and methods in language teaching. Approa- ches and methods in language teaching. Cambridge: Cambridge University Press.

Richards, J. (2017). Principles of the Eclectic Approach. Recuperado de https://www. professorjackrichards.com/principles-ofthe-eclectic-approach/

Rico, C. (2015). Polis: Speaking Ancient Greek as a Living Language. Jerusalén: Polis Institute Press.

Roehl, A., Reddy, S. L. y Shannon, G. J. (2013). The Flipped Classroom: An Opportunity to Engage Millennial Students Through Active Learning Strategies. Journal of Family \& Consumer Sciences, 105(2), 44-49. doi:10.14307/JFCs105.2.12

Ros Martínez de Lahidalga, I. (2008). Moodle, la plataforma para la enseñanza y organización escolar. Ikastorratza, e-Revista de Didáctica, (2), 1-12.

Salazar, L. y Batista, J. (2005). Hacia la consolidación de un enfoque ecléctico en la enseñanza de idiomas extranjeros. Paradigma, XXVI(1), 1-19.

Sánchez Santamaría, J., Sánchez Antolín, P. y Ramos Pardo, F.J. (2012). Usos pedagógicos de Moodle en la docencia universitaria desde la perspectiva de los estudiantes. Revista Iberoamericana de Educación, (60), 15-38.

Santiago, R. (2018). What is the Flipped Classroom? Recuperado de https://www. theflippedclassroom.es/what-is-innovacion-educativa/

Shamil (2018). What is Quizizz? Recuperado de https://quizizz.zendesk.com/hc/enus/articles/115000338045-Getting-Started-with-Quizizz

Sluijsmans, D., Dochy, F. y Moerkerke, G. (1998). Creating a Learning Environment by Using Self-, Peer- and Co-Assessment. Learning Environments Research, 1(3), 293-319. 
Steel, C. y Primavesi, O. (2013). Aristotle's Metaphysics Alpha: Symposium Aristotelicum. Oxford: Oxford University Press.

Taylor, S. y Bogdan, R. (1992). Introducción a los métodos cualitativos de investigación. La búsqueda de significados. Barcelona: Paidós.

\section{Anexo 1. Ítems de la autoevaluación}

Del vocabulario del fragmento de la Metafísica estudiado en clase, he memorizado:

- Poquísimas palabras

- Pocas palabras

- Suficientes palabras

- Muchas palabras

- Todas las palabras

1) ¿Reconozco las distintas formas que toman los sustantivos según el caso y la declinación a la que pertenecen $\left(1^{\mathrm{a}}\right.$ (tema en $\left.-\alpha\right), 2^{\mathrm{a}}$ (tema en -o) y $3^{\mathrm{a}}$ declinación (en consonante $y$ temas en $-\mathrm{e} e-\mathrm{v}))$ ?

- Nunca

- Con dificultad

- En algunas ocasiones

- En la mayoría de las ocasiones

- Siempre

2) ¿Identifico las formas propias de las voces activa y media de indicativo presente?

- Nunca

- Con dificultad

- En algunas ocasiones

- En la mayoría de las ocasiones

- Siempre

3) ¿Reconozco los infinitivos (- $\varepsilon v / \varepsilon \sigma \theta \alpha \imath)$ sustantivados (con artículo) y su función?

- Nunca

- Con dificultad

- En algunas ocasiones

- En la mayoría de las ocasiones

- Siempre
Tucker, B. (2012). The Flipped Classroom: Online instruction at home frees class time for learning. Education Next, 12(1), 1-4.

Woźniak, P. (2018). SuperMemo. Recuperado de https://www.supermemo.com/english/contents.htm\#Articles

4) ¿Identifico los participios sustantivados (con artículo) y su función?

- Nunca

- Con dificultad

- En algunas ocasiones

- En la mayoría de las ocasiones

- Siempre

5) ¿Reconozco la estructura de las oraciones finales con ivo?

- Nunca

- Con dificultad

- En algunas ocasiones

- En la mayoría de las ocasiones

- Siempre

6) ¿Identifico las formas de singular y plural?

- Nunca

- Con dificultad

- En algunas ocasiones

- En la mayoría de las ocasiones

- Siempre

7) ¿Puedo interpretar y traducir correctamente un texto en griego de mediana dificultad?

- Nunca

- Con dificultad

- En algunas ocasiones

- En la mayoría de las ocasiones

- Siempre

8) ¿Resuelvo los ejercicios y hago las tareas que deja el profesor?

- Nunca

- Con dificultad

- En algunas ocasiones

- En la mayoría de las ocasiones

- Siempre 
9) Teniendo en cuenta las respuestas a las anteriores preguntas, mi nota de autoevaluación es de 0,0 a 5.0 :

\section{Apéndice 2. Encuesta sobre la percepción de la unidad didáctica}

El diseño y la organización de la unidad me parecieron en términos generales:

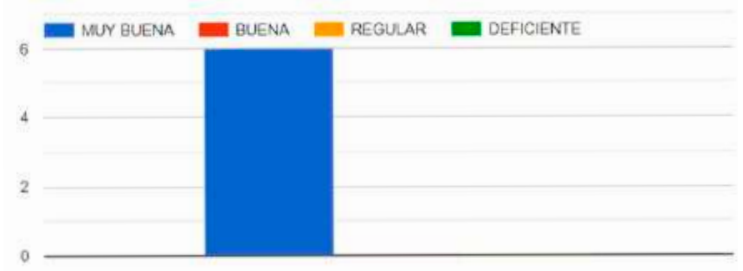

Figura 10. Percepción del diseño y la organización de la unidad

Selección de comentarios y sugerencias:

- Podría ser estéticamente más bonita, pero en cuanto a contenido todo muy bien.

- La organización se ve bien, es agradable y clara.

- Me parece interactiva y una forma alternativa -y más eficiente en nuestros díaspara aprender el texto de la Metafisica de Aristóteles.

- El diseño es muy bueno, sobre todo porque ahora las clases son más didácticas e incluso es más fácil aprender.

Las actividades me parecieron:

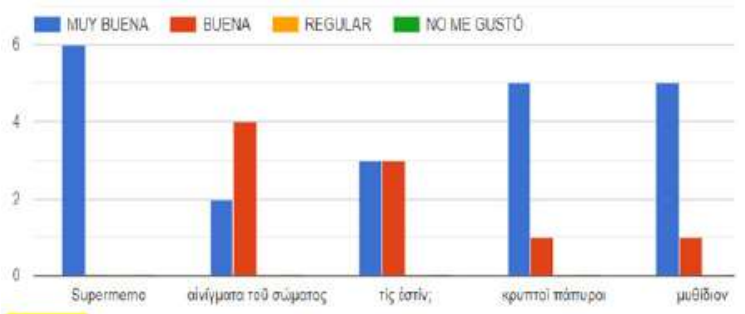

Figura 11. Percepción de las nuevas actividades de clase
10)Comentarios, sugerencias, observaciones, quejas, etc.

Selección de comentarios y sugerencias:

- Las diversas actividades son entretenidas y motivan a desarrollarlas.

- SuperMemo es una herramienta especialmente útil.

- Me encantaron todas las actividades, en

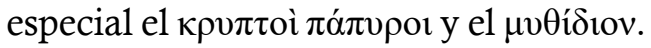

- Las actividades han sido interesantes. En concreto, han sido una buena herramienta para aprender un poco más el vocabulario, que es complicado de memorizar.

- Igualmente, me han parecido muy buenas, en especial SuperMemo. Aprender el vocabulario es mucho más fácil y siento que el aprendizaje desde lo más básico, como las partes del cuerpo, ayuda muchísimo al rendimiento.

Los videos me parecieron:

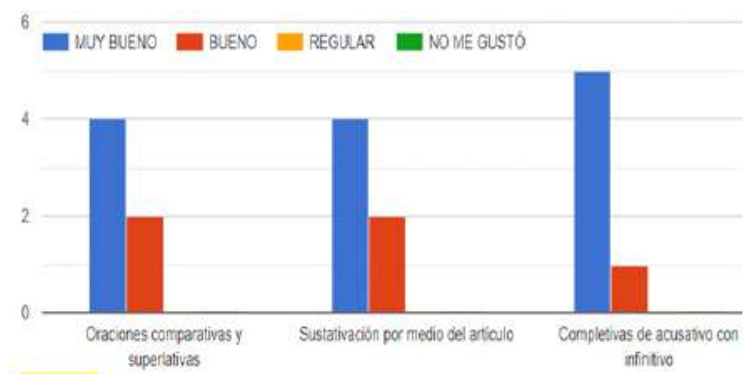

Figura 12. Percepción de los videos que explican gramática

Selección de comentarios y sugerencias:

- Son claros y los ejemplos ayudan a entender mejor.

- Las voces a veces no son tan nítidas. 
- Muy buenos, pero me hubiera gustado que no fueran tan rápidos y explicaran con otros ejemplos.

- Han sido muy graciosos, pero también un modo interactivo de aprender gramática griega, en el caso de la Metafisica.

- Los videos son muy creativos y divertidos y, además son muy útiles. Sin embargo, la sola utilización del griego en todo el video suele ser algo más difícil.

$\bullet$

La utilización de OneNote ${ }^{\circledR}$ para preparar y trabajar la introducción de la Metafisica de Aristóteles (980a-982a) me pareció:

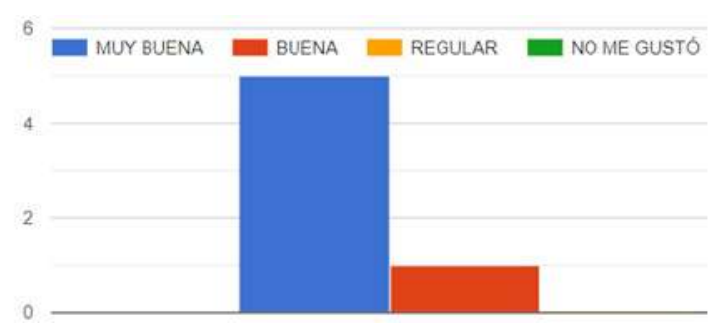

Figura 13. Percepción de la utilización de OneNote ${ }^{\circledR}$

Selección de comentarios y sugerencias:

- Me parece que el uso de OneNote ${ }^{\circledR}$ es acertado, aparte de que está muy bien organizado.
- Lo único que no me gustó fueron los problemas técnicos.

- Esta me ha parecido más interesante, pues realmente empezamos la labor de traducción del texto, con varias herramientas actuales que nos funcionan.

- Es sumamente útil, porque cada palabra tiene un hipervínculo al diccionario.

Figura 14 Percepción del método de evaluación

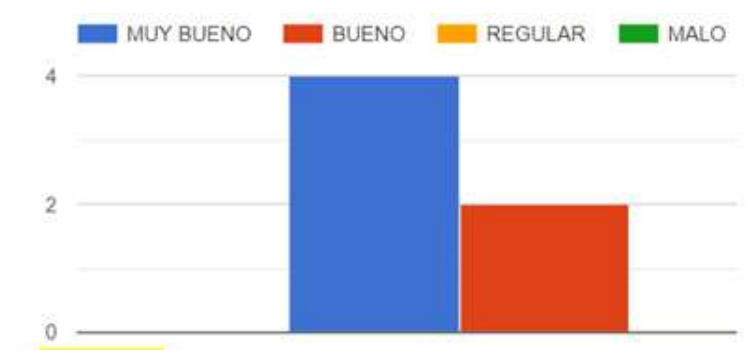

El método de evaluación de la asignatura, que incluye autoevaluación, coevaluación y evaluación, me ha parecido:

- La autoevaluación sirve mucho para darse cuenta de qué se tiene que mejorar.

- Buenas, no tengo comentarios. Lo único que pienso es que la nota de autoevaluación no debería contar en el porcentaje de nota, pues es muy subjetiva.

- Sí, evalúa todas las áreas que se espera de un estudiante en su comprensión del idioma griego.

Cómo citar este artículo: Forero-Álvarez, R. y Triana-Perdomo, L. A. (2019). Tecnologías del aprendizaje y el conocimiento (TAC) para la traducción de Aristóteles Metafísica 980a-982a. Mutatis Mutandis. Revista Latinoamericana de Traducción, 12(1), 182-208. Dor: https://doi.org/10.17533/udea.mut.v12n1a02 